\title{
A Novel Method for Managing Postthyroidectomy or Parathyroidectomy Hematoma: Single-Institution Experience With More Than 4000 Central Neck Operations
}

\author{
Sabaretnam Mayilvaganan • Ritesh Agrawal • \\ Sudhi Agarwal
}

Published online: 9 April 2014

(c) Société Internationale de Chirurgie 2014

\section{To the Editor}

We read the article by Dixon et al. [1] with interest and congratulate the authors for their novel method of treating hematomas following thyroid and parathyroid surgery under local anesthesia and also for sharing their challenges in managing these hematomas. Hematomas following thyroid and parathyroid surgeries are at times ephemeral instead of obvious, with no definitive bleeding identified. The surgeon then needs all of his or her experience to tackle this dreaded complication, which has resulted in many surgeons not opting for day surgeries. However, there are certain observations in the article by Dixon et al. that need further clarification and comments that can be of use for future researchers.

For instance, did the inexperience of the surgeon result in an increased incidence of hematomas [2]? Did patient characteristics such as muscularity of the individual or hypertension play a role [3]? Did the authors analyze factors such as the size of the goiter and/or retrosternal extension to determine if they increased the incidence of hematoma.

S. Mayilvaganan $(\bowtie)$

Department of Endocrine and Breast Surgery, Vydehi Institute of Medical Sciences and Research Institute, Bengaluru 560066, India

e-mail: drretnam@gmail.com

R. Agrawal

Department of General Surgery, Aarupadai Veedu Medical College, Kirumampakkam, Puducherry 607402, India

S. Agarwal

Department of Endocrine and Breast Surgery, Subharathi Institute of Medical Sciences, Meerut, India
As the duration of this study was over a period of 16 years, did the introduction of newer techniques (e.g., sutureless thyroidectomy) and the learning curves result in increased hematomas [4]? Were surgical factors analyzed, such as the type of suture material used for ligation and whether routine use of hemostatic agents (e.g., oxidized cellulose polymer) played a role? We agree with the authors about not using drains routinely [5], but did the authors use a drain after reexploration?

Finally, were the patients educated preoperatively about these possible complications? Did a member of the operating team assess the patients before they were discharged?

\section{References}

1. Dixon JL, Snyder SK, Lairmore TC, et al (2014) A novel method for the management of post-thyroidectomy or parathyroidectomy hematoma: a single-institution experience after over 4,000 central neck operations. World J Surg. doi: 10.1007/s00268-013-2425-7. (in press)

2. Shaha A, Jaffe BM (1988) Complications of thyroid surgery performed by residents. Surgery 104:1109-1114

3. Amit M, Binenbaum Y, Cohen JT et al (2013) Effectiveness of an oxidized cellulose patch hemostatic agent in thyroid surgery: a prospective, randomized, controlled study. J Am Coll Surg 217:221-225

4. Schiphorst AH, Twigt BA, Elias SG et al (2012) Randomized clinical trial of LigaSure versus conventional suture ligation in thyroid surgery. Head Neck Oncol 4:2

5. Samraj K, Gurusamy KS (2007) Wound drains following thyroid surgery. Cochrane Database Syst Rev 4:CD006099 